\title{
Impact of health education on unmet needs of contraception in urban slums of Chandigarh, India
}

\author{
Dinesh Kumar, Meenu Kalia*, N. K. Goel, M.K. Sharma
}

Department of Community Medicine, GMCH, Chandigarh, India

Received: 16 May 2016

Accepted: 07 June 2016

\section{*Correspondence:}

Dr. Meenu Kalia,

E-mail: meenusharma75@gmail.com

Copyright: (c) the author(s), publisher and licensee Medip Academy. This is an open-access article distributed under the terms of the Creative Commons Attribution Non-Commercial License, which permits unrestricted non-commercial use, distribution, and reproduction in any medium, provided the original work is properly cited.

\begin{abstract}
Background: Unmet need points to gap between some women reproductive intention and their contraceptive behavior. Unmet need for contraception is mainly attributed to lack of information, negative attitude, fear of adverse effects and social influences. The objective of this study was to investigate awareness and practice of contraceptive usage. And to estimate unmet need of contraception in the studied population and to identify the factors associated with it, and to evaluate impact of health education on unmet needs of contraception.

Methods: A community-based longitudinal study was conducted in four randomly selected urban slum areas (colonies) of Chandigarh, India. A systematic two-stage random sample design was adopted.

Results: Overall contraceptive awareness rates among women and men were increased from $84.1 \%$ to $96.3 \%$ and from $82.2 \%$ to $95.5 \%$ in post-interventional survey as compared to baseline survey. Contraceptive prevalence rates were found to be $57.3 \%$ and $65.5 \%$ respectively in pre interventional and post interventional surveys, against contraceptive awareness rates of $81.7 \%$ and $95.5 \%$ respectively, resulting in gaps between knowledge and practice to be unmet needs of contraception to the extents of $24.4 \%$ and $30.0 \%$ respectively in the two surveys.

Conclusions: There is an urgent need of adopting some population specific integral strategies for changing social norms and attitudes of couples regarding reproductive issues, increase in contraceptives awareness as well as practice for reductions in unmet needs of contraception and unwanted/unplanned pregnancies.
\end{abstract}

Keywords: Unmet needs, Improvident maternity, Reproductive health needs, Reproductive intention

\section{INTRODUCTION}

Population explosions in developing countries are the major problem which neutralizes all the gains and developments achieved in the country. Alarmingly rising population has its deleterious effect on developmental efforts. This problem has been addressed as the main objective in the national population policy (NPP), $2000 .{ }^{1}$ The contraceptive prevalence rate in India was found to be 56 percent in NFHS-3 Survey. $^{2}$ Steady increase in the CPR from 41 percent in NFHS-1(1992-93) to 48 percent in NFHS-2 (1998-99). One of the main reasons for population growth is the low prevalence rate of contraceptive use. In India, in spite of availability of many contraceptive techniques, the couple protection rate (CPR) continues to be inadequate. Contraception as a behavioural phenomenon has been the focus of many population researches. Most couples in India do not want to use a contraceptive method on a long-term basis for the fear of side-effects, or do not like to use a method linked with coitus. Hence, unwanted and unplanned pregnancies are quite common leading to improvident maternity. Improvident maternity is defined as women who had already given birth to three children of whom at least one is alive. Many women who want to space or limit births do not currently use contraceptive. There is a gap between the desire to use the contraceptive method and the actual use of contraceptive method. The concept of unmet need points to gap between some women reproductive intention and their contraceptive behaviour. This gap, called the unmet need for contraception, is mainly attributed to lack of information, negative 
attitude, fear of adverse effects and social influences. Unmet need for family planning is an important indicator for assessing the potential demand for family planning services. In doing so, it poses a challenge to family planning programmes. Meeting this unmet need for contraception is one of the top priorities for family planning programs. NFHS-3 Survey, currently married women who are not using any method of contraception but who do not want any more children are defined as having an unmet need for limiting and those who are not using contraception but want to wait two or more years before having another child are defined as having an unmet need for spacing. ${ }^{2}$ The sum of the unmet need for limiting and the unmet need for spacing is the unmet need for family planning. The total demand for family planning is the sum of unmet need and met need. Among the common reasons reported for unmet need are inconvenient or unsatisfactory services, lack of information, fears about contraceptive side effects and opposition from husbands, relatives or others. In a study while studying men's knowledge, awareness and extent of their participation in the key areas of reproductive and child health looked at agreement between husbands and wives on the unmet need for family planning. ${ }^{3}$ Correlates of unmet need of contraception are population specific showing regional variations. Present study aims at finding the extent and factors influencing unmet need of contraception and also to evaluate impact of health education interventions on it. The study presents some of results of a detailed survey conducted under ICMR funded project undertaken in urban slums of Chandigarh with the following specific objectives:

The objective of this study was to investigate awareness and practice of contraceptive usage. And to estimate unmet need of contraception in the studied population and to identify the factors associated with it. And to evaluate impact of health education on unmet needs of contraception.

\section{METHODS}

A systematic two-stage random sample design was adopted. At the first stage, from the sampling frame available a sample of four slum areas (primary stage units) was selected systematically with probability proportion to size (PPS). At the second stage, a sample of households as second stage units was selected within each selected PSU of an optimum size with proportional allocation. Cluster randomization was done to assess the impact of health education interventions on unmet need of contraception. Out of four randomly selected clusters, two clusters were randomly assigned to study group and remaining two clusters were assigned to control group. At the baseline/pre-intervention survey (survey-I), the knowledge regarding contraceptive and reproductive behavior of couples was assessed for all selected couples in four randomly selected slum areas (colonies). Couples of study group selected in the baseline survey were provided interventions in terms of health education regarding reproductive health/fertility related issues. No active intervention was given to study subjects belonging to control group. Post intervention survey was conducted in all four selected clusters. Outcome parameters in both the groups were compared. All respondents (women and their spouses) within selected households were interviewed separately in privacy to collect the desired information. A few couples who were lost to follow-up due to any reason such as migration etc. were excluded from analysis.

The design of this study was community-based longitudinal study was conducted in four randomly selected urban slum areas (colonies) of Chandigarh, India.

The units of this study was couples having wife in the reproductive age (15-49 years) along with their spouses willing to participate in the study through-out the study period served as study units or respondents.

The optimum sample size was power analysis was done to calculate optimum sample size for the proposed cross sectional study using the following formula with approximation for large population:

$\mathrm{N}_{\text {opt. }}=\frac{\mathrm{Z}_{1-\alpha / 2}^{2}(1-\mathrm{P})}{\epsilon^{2} \mathrm{P}}$,

Where,

$\mathrm{P}=$ Anticipated population proportion

$1-\alpha=$ Confidence coefficient

$\in=$ Relative precision, and

$\mathrm{Z}$ (.) is the value of standard normal variate.

Sample of an optimum size of 634 couples, having wife in the reproductive age (15-49 years) was attained. Optimum sample size was further elevated by $20 \%$ in order to adjust drop-outs and accordingly it was initially planned to cover 760 couples. Subsequently respondents who were lost to follow-up were excluded from analysis and ultimate sample included results of 667 couples only.

Variables of this study was information on socio-cultural and demographic characteristics, reproductive/fertility behavior and several other variables was collected using a predesigned and pretested semi-structured interview schedule by conducting house-to-house survey. Respondents were interviewed in privacy to collect the desired information. The interview was conducted at the respondent's home. Both husband and wife were interviewed by the same interviewer. All possible efforts were made to reduce non-responses including frequent visits. Approval by institutional ethics committee (IEC) was granted. 


\section{RESULTS}

Table 1: Baseline demographic characteristics by current contraceptive use.

\begin{tabular}{|c|c|c|c|}
\hline Characteristic & $\mathbf{N}$ & $\begin{array}{l}\text { Users } \\
\text { number } \\
(\%)\end{array}$ & $\begin{array}{l}\text { Non users } \\
\text { number } \\
(\%)\end{array}$ \\
\hline \multicolumn{4}{|l|}{ Age of wife } \\
\hline$<18$ & 11 & $1(9.1)$ & $10(90.9)$ \\
\hline $18-25$ & 204 & $97(47.5)$ & $107(52.5)$ \\
\hline $26-35$ & 319 & $196(61.4)$ & $123(38.6)$ \\
\hline $36-49$ & 133 & $88(66.2)$ & $45(33.8)$ \\
\hline \multirow[t]{2}{*}{ Mean \pm SD } & & $30.68 \pm 6.56$ & $28.33 \pm 6.91$ \\
\hline & & \multicolumn{2}{|c|}{$(\mathrm{P}<0.001)$} \\
\hline \multicolumn{4}{|l|}{ Age of husband } \\
\hline $19-25$ & 116 & $48(41.4)$ & $68(58.6)$ \\
\hline $26-35$ & 328 & $186(56.7)$ & $142(43.3)$ \\
\hline $36-49$ & 211 & $142(67.3)$ & $69(32.7)$ \\
\hline$>49$ & 12 & $6(50.0)$ & $6(50.0)$ \\
\hline \multirow[t]{2}{*}{ Mean \pm SD } & & $34.83 \pm 7.54$ & $31.69 \pm 7.24$ \\
\hline & & \multicolumn{2}{|c|}{$(\mathrm{P}<0.001)$} \\
\hline \multicolumn{4}{|l|}{ Marital age of wife } \\
\hline $10-14$ & 48 & $27(56.3)$ & $21(43.7)$ \\
\hline $15-17$ & 145 & $86(59.3)$ & $59(40.7)$ \\
\hline $18-20$ & 263 & $161(61.2)$ & $102(38.8)$ \\
\hline $21-22$ & 114 & $60(52.6)$ & $54(47.4)$ \\
\hline $23-25$ & 83 & $42(50.6)$ & $41(49.4)$ \\
\hline Above 35 & 13 & $6(46.2)$ & $7(53.8)$ \\
\hline \multirow[t]{2}{*}{ Mean \pm SD } & & $18.59 \pm 3.24$ & $18.44 \pm 3.23$ \\
\hline & & \multicolumn{2}{|c|}{$(\mathrm{P}=0.37)$} \\
\hline \multicolumn{4}{|c|}{ Marital age of husband } \\
\hline $10-14$ & 14 & $6(42.9)$ & $8(57.1)$ \\
\hline $15-17$ & 58 & $36(62.1)$ & $22(37.9)$ \\
\hline $18-20$ & 87 & $49(56.3)$ & $38(43.7)$ \\
\hline $21-22$ & 194 & $115(59.3)$ & $79(40.7)$ \\
\hline $23-25$ & 229 & $131(57.2)$ & $98(42.8)$ \\
\hline Above 35 & 85 & $45(52.9)$ & $40(47.1)$ \\
\hline \multirow{2}{*}{ Mean \pm SD } & & $21.44 \pm 3.43$ & $21.74 \pm 3.79$ \\
\hline & & \multicolumn{2}{|c|}{$(\mathrm{P}=0.34)$} \\
\hline \multicolumn{4}{|l|}{ Family type } \\
\hline Nuclear & 419 & $253(60.4)$ & $166(39.6)$ \\
\hline \multirow[t]{2}{*}{ Joint/extended } & 248 & $129(52.0)$ & $119(48.0)$ \\
\hline & & \multicolumn{2}{|c|}{$\mathrm{X}^{2}=4.45(\mathrm{P}=0.03)$} \\
\hline \multicolumn{4}{|c|}{ Improvident maternity status } \\
\hline No & 376 & $192(51.9)$ & $184(48.9)$ \\
\hline \multirow[t]{2}{*}{ Yes } & 291 & $190(65.3)$ & $101(34.7)$ \\
\hline & & \multicolumn{2}{|c|}{$\mathrm{X}^{2}=13.6(\mathrm{P}<0.001)$} \\
\hline \multicolumn{4}{|l|}{ Prior place of living } \\
\hline Within Chandigarh & 356 & $195(54.8)$ & $161(45.2)$ \\
\hline \multirow{2}{*}{\multicolumn{2}{|c|}{ Outside Chandigarh 311}} & $187(60.1)$ & $124(39.9)$ \\
\hline & & \multicolumn{2}{|c|}{$\mathrm{X}^{2}=1.94(\mathrm{P}=0.16)$} \\
\hline \multicolumn{4}{|c|}{ Socio-economic status } \\
\hline Middle/high & 72 & $40(55.6)$ & $32(44.4)$ \\
\hline Low & 595 & $342(57.5)$ & $253(42.5)$ \\
\hline & & \multicolumn{2}{|c|}{$\mathrm{X}^{2}=0.097(\mathrm{P}=0.75)$} \\
\hline
\end{tabular}

\begin{tabular}{|c|c|c|c|}
\hline \multicolumn{4}{|c|}{ Having female child } \\
\hline No female & 440 & $276(62.7)$ & $164(37.3)$ \\
\hline At least one & 227 & $106(46.7)$ & $121(53.3)$ \\
\hline & & \multicolumn{2}{|c|}{$\mathrm{X}^{2}=15.7(\mathrm{P}<0.001)$} \\
\hline \multicolumn{4}{|c|}{ Having male child } \\
\hline No male & 493 & $306(62.1)$ & $187(37.9)$ \\
\hline At least one & 174 & $76(43.7)$ & $98(56.3)$ \\
\hline & & \multicolumn{2}{|c|}{$\mathrm{X}^{2}=17.8(\mathrm{P}<0.001)$} \\
\hline \multicolumn{4}{|c|}{ More daughters than sons } \\
\hline No & & $257(56.5)$ & $198(43.5)$ \\
\hline Yes & & $125(59.0)$ & $87(41.0)$ \\
\hline & & \multicolumn{2}{|c|}{$\mathrm{X}^{2}=0.36(\mathrm{P}=0.55)$} \\
\hline \multicolumn{4}{|c|}{ Last pregnancy wanted } \\
\hline No & 320 & $192(60.0)$ & $128(40.0)$ \\
\hline Yes & 347 & $190(54.8)$ & $157(45.2)$ \\
\hline & & \multicolumn{2}{|c|}{$\mathrm{X}^{2}=1.87(\mathrm{P}=0.17)$} \\
\hline Overall & 667 & $382(57.3)$ & $285(42.7)$ \\
\hline
\end{tabular}

Table 1 presents comparison of baseline characteristics of current contraceptive users and non-users. Contraceptive prevalence rate (CPR) was found to be maximum $(66.2 \%)$ among women aged $36-49$ years, and it was also maximum $(67.3 \%)$ in case of their spouses belonging to this age group. Mean ages of women using contraceptives was found to be $30.68 \pm 6.56$ and that for non-user women $28.33 \pm 6.91$ years with highly significant difference $(\mathrm{P}<0.001)$. Similarly for this age group 36-49 years for men, $142(67.3 \%)$ contraceptive prevalence rate was observed. Mean ages of men using contraceptives and not using any contraceptive were found to be $34.83 \pm 7.54$ and $31.69 \pm 7.24$ years respectively. This difference was also found to be highly significant $(\mathrm{P}<0.001)$. Contraceptive use was more prevalent in case of elderly and younger ages at marriage for men and women. Mean ages at marriage were found to be $18.59 \pm 3.24$ for users and $18.44 \pm 3.23$ for non-user women. Similarly, Mean ages at marriage were found to be $21.44 \pm 3.43$ for users and $21.74 \pm 3.79$ for non-user men. These mean ages for both women and men were not found to differ significantly in the two groups. Contraceptive use was more common in case of nuclear families $(60.4 \%)$ as compared to their counterparts $(52.0 \%)$. Type of family was significantly associated $(\mathrm{P}=0.03)$ with contraceptive use. Prior place of living was not found to be a significant correlate $(\mathrm{P}=0.16)$ of contraceptive use. Contraceptive prevalence rate in case of improvident maternity (63.4\%) was significantly higher $(\mathrm{P}=0.005)$ as compared to that for nonimprovident couples $(52.4 \%)$. Contraceptive use was also significantly associated $(\mathrm{P}=0.005)$ with improvident maternity. No significant association $(\mathrm{P}=0.75)$ was observed between contraceptive use and SES. Contraceptive use by couples having no male child was also increased significantly in case of $(62.1 \%)$ as compared to among those having at least one male child $(43.7 \%)$. There was significant association $(\mathrm{P}<0.001)$ between contraceptive use and having male child. Desire for last pregnancy was not found to be a significant correlate of contraceptive use $(\mathrm{P}=0.17)$. 
Table 2: Contraceptive behaviour and unmet needs of contraception in study and control group.

\begin{tabular}{|c|c|c|c|c|}
\hline \multirow{3}{*}{ Outcome parameter } & \multicolumn{2}{|c|}{ Study group } & \multicolumn{2}{|c|}{ Control group } \\
\hline & Survey-I & Survey-II & Survey-I & Survey-II \\
\hline & 348 & 348 & 319 & 319 \\
\hline \multicolumn{5}{|l|}{ Contraceptive awareness and practice } \\
\hline Contraceptive knowledge of wife & $275(79.0)$ & $333(95.7)$ & $286(89.7)$ & 309 (96.9) \\
\hline Contraceptive knowledge of husband & $263(75.6)$ & $330(94.8)$ & $285(89.3)$ & $307(96.2)$ \\
\hline Contraceptive knowledge of couples & $278(79.9)$ & $333(95.7)$ & $286(89.7)$ & $308(96.6)$ \\
\hline Current contraceptive prevalence & $201(57.7)$ & $237(68.1)$ & $181(56.7)$ & $200(62.6)$ \\
\hline Use of permanent method & $70(20.1)$ & $87(25.0)$ & $79(24.8)$ & $92(28.8)$ \\
\hline Unmet need of contraception & $82(41.2)$ & $51(29.6)$ & $46(38.0)$ & $40(35.5)$ \\
\hline $\begin{array}{l}\text { Use of permanent methods among couples having no } \\
\text { desire for last child }\end{array}$ & $51(25.6)$ & $58(33.7)$ & 37 (30.6) & $34(29.3)$ \\
\hline \multicolumn{5}{|l|}{ Wanted birth spacing } \\
\hline Uncertain/unplanned & $184(52.9)$ & $204(58.6)$ & $220(68.9)$ & $220(68.9)$ \\
\hline Wanted & $73(21.0)$ & $64(18.4)$ & $87(27.3)$ & $78(24.5)$ \\
\hline Not wanted/completed family size & $81(23.3)$ & $80(23.0)$ & $12(3.8)$ & $21(6.6)$ \\
\hline \multicolumn{5}{|l|}{ Use of spacing methods } \\
\hline Among couples with uncertain/unplanned birth spacing & $154(83.7)$ & $153(75.0)$ & $166(75.5)$ & $159(72.3)$ \\
\hline Among couples wanted birth spacing & $59(80.8)$ & $51(79.7)$ & $67(77.0)$ & $59(75.6)$ \\
\hline $\begin{array}{l}\text { Among couples not wanted birth spacing /completed } \\
\text { family size }\end{array}$ & $65(71.4)$ & $57(71.3)$ & $7(58.3)$ & $9(42.9)$ \\
\hline Overall use of spacing methods & $278(79.9)$ & $261(75.0)$ & $240(75.2)$ & $227(71.2)$ \\
\hline
\end{tabular}

Table 2 shows comparison of some fertility related outcome parameters of interest in the study and control groups. Contraceptive knowledge of women as well as their spouses was found to increase significantly in both the groups. Extent of changes in knowledge status of couples regarding contraception were comparatively more in study group (from $79.9 \%$ to $95.7 \%$ ) as compare to that in control group (from $89.7 \%$ to $96.6 \%$ ).Hence, health education can play an important role in increasing awareness regarding contraception. Also changes in contraceptive prevalence rates in study group (from $57.7 \%$ to $68.1 \%$ ) was comparatively more in study group as compare to that in control group (from $56.7 \%$ to $62.6 \%$ ). There was increase in both awareness and practice of spacing as well as permanent methods for both groups but better outcomes were observed for study group. For the study group, unmet need of contraception was reduced from existing level of 41.2 to $29.6 \%$ while it came down from $38.0 \%$ found in baseline survey to only $35.5 \%$ for the control group. Use of permanent methods increased among couples who have already attained their desired family size. Proportion of unplanned pregnancies showed more increments for study group as compared to that for control group. Spacing methods were being used even without proper planning and objectives, even by those couples who wanted no more children.

\section{DISCUSSION}

PPROM complicates only $3 \%$ of pregnancies but is highly significant gaps $(\mathrm{P}<0.001)$ between knowledge and practice of contraception in both the groups were observed in the present study between knowledge and practices of contraception. Contraceptive prevalence rates were found to be $57.3 \%$ and $65.5 \%$ respectively in pre interventional and post interventional surveys, against contraceptive awareness rates of $81.7 \%$ and $95.5 \%$ respectively resulting in gaps between knowledge and practice to the extents of $24.4 \%$ and $30.0 \%$ respectively in the two surveys.

CPR was found to be about $49.9 \%$ in Dehradun about $48 \%$ of couples of $15-45$ years. $^{4}$ of age were reported practicing family planning methods in India. ${ }^{5}$ Contraceptive 'ever users' rate was found to be $75 \%$ in Delhi. ${ }^{6}$ Whereas, almost half of the subjects were using some family planning methods in Orissa and about $1 / 3^{\text {rd }}$ of them relied on traditional method of contraception. ${ }^{7}$ In the rest of respondents female sterilization predominated. The contraceptive acceptance was higher among improvident women who had one or more living sons.

In the present study, among couples having undesired last pregnancy, $60.0 \%$ in pre-intervention survey and $68.4 \%$ in post intervention survey were using at least one contraceptive, meaning thereby unmet needs of contraception to be $40.0 \%$ and $31.6 \%$ in the two surveys respectively as they were not using any method of contraception in spite of no desire of child/undesired last pregnancy. 
The NFHS- 2 reported that nearly 16 per cent of currently married women had an unmet contraceptive need, 8.3 per cent for spacing and 7.5 per cent for limiting. ${ }^{8}$ According to UNPF report (2004) about 2001 million women had unmet need of effective contraception. ${ }^{9}$ High degree of agreement/concordance $(93.5 \%)$ regarding unmet need of family planning amongst women and their spouses were observed in an earlier study and females reported greater unmet need of family planning. Among 82.5\%) of these cases both husbands and wives did not have unmet need of family planning. In $6.5 \%$ cases both had unmet need. ${ }^{10}$

Changes in contraceptive prevalence rates in study group (from $57.7 \%$ to $68.1 \%$ ) was comparatively more in study group as compare to that in control group (from $56.7 \%$ to $62.6 \%$ ). For the study group, unmet need of contraception was reduced from existing level of 41.2 to $29.6 \%$ while it came down from $38.0 \%$ found in baseline survey to only $35.5 \%$ for the control group.

\section{CONCLUSION}

Present study reported high degree of unmet need. Health education can play an important role in increasing awareness and practice of contraception. It was also helpful in reduction of unwanted pregnancies and addressing other reproductive health needs by reducing unmet needs of contraception.

\section{ACKNOWLEDGEMENTS}

Present study is a part of Indian council of medical research (ICMR) sponsored project "correlates of improvident maternity conducted in urban slum areas of Chandigarh, India" (IRIS ID No. 2006-055) Authors are grateful to Indian council of medical research (ICMR), New Delhi, India for providing financial assistance and also to project staff for their respective contributions.
Funding: No funding sources Conflict of interest: None declared

Ethical approval: The study was approved by the Institutional Ethics Committee

\section{REFERENCES}

1. National population policy, ministry of health and family welfare, Govt. of India. New Delhi; 2000.

2. National family health survey (NFHS-3). 2006-07, International institute for population sciences, Mumbai, India. ORC Macro, Maryland, USA; 2000.

3. Dutta M, Kapilashrami MC, Tiwari VK. Knowledge, awareness and extent of male participation in key areas of reproductive and child health in an urban slum of Delhi. Health and Population-Perspectives and Issues. 2004;27(2)49-66.

4. Kansal A, Chandra R, Kandpal SD, Negi KS. Epidemiological correlates of contraceptive prevalence in rural population of Dehradun district. Indian Journal of Community Medicine. 2005;30(2):60-2.

5. Sharma RS, Rajalakshmi M, Sharma RS, Jeyaraj DA. Current status of fertility control methods in India. J Biosci. 2001;26(4 Suppl):391-405.

6. Kumar PB. Prevalence of usage of difference contraceptive methods in East Delhi- a cross sectional study. Indian Journal of Community Medicine. 2005;30(2):53.

7. Kirkkola AL, Maltlila K, Virjo I. Problems with condoms-a population based study among finish men and women. European Journal of Contraception and reproductive health care. 2005;10:87-92.

8. National family health survey (NFHS-2), India 199899. International Institute for Population Science (IIPS) and ORC Macro; 2001.

9. UNPF (2004). Report of the International conference on population and development, Cairo; 1994.

10. Yadav, Singh KB, Goswami K. Unmet family planning need: differences and levels of agreement between husband-wife, Haryana India. Indian Journal of Community Medicine. 2009;34(3):188-92.

Cite this article as: Kumar D, Kalia M, Goel NK, Sharma MK. Impact of health education on unmet needs of contraception in urban slums of Chandigarh, India. Int J Reprod Contracept Obstet Gynecol 2016;5:2317-21. 